\title{
Are yuppies and muppies more physically active than the others aged 20-39?
}

\author{
Elżbieta Biernat $^{1, *}$, Monika Piątkowska ${ }^{2}$, and Justyna Krzepota ${ }^{3}$ \\ ${ }^{\text {I} C o l l e g i u m ~ o f ~ W o r l d ~ E c o n o m y, ~ S G H ~ W a r s a w ~ S c h o o l ~ o f ~ E c o n o m i c s, ~ W a r s a w, ~ P o l a n d ; ~}{ }^{2}$ Faculty of Physical Education, Josef \\ Pilsudski University of Physical Education in Warsaw, Warsaw, Poland; and ${ }^{3}$ Department of Physical Culture and Health \\ Promotion, University of Szczecin, Szczecin, Poland
}

Copyright: (c) 2020 E. Biernat et al. This is an open access article licensed under the Creative Commons Attribution License (https://creativecommons.org/licenses/by/4.0/).

\begin{abstract}
Background: Values of young urban professionals (yuppies) are still valid and it is possible to find references to the lifestyle of young people. This also applies to the younger generation, in other words, middle-aged urban professionals (muppies). Objective: The aim is evaluating whether yuppies and muppies can be a role model for society in the field of taking care of leisure-time physical activity (PA). Methods: Surveys were conducted by an Omnibus survey on the representative sample of Poles in two studies $(N=1053, N=1067)$. Persons aged 20-39 $(N=762$ were selected) and based on the criteria: education, residence in cities, study skills character of work, income, there was created a yuppie/muppie group $(n=67)$ and non-yuppies $(n=695)$. International Physical Activity Questionnaire - Long Form was used. Results: Recommendations of WHO were met by $43.3 \%$ of yuppies/muppies and $33.4 \%$ of non-yuppies. No significant differences between groups were observed $(p=.103)$ in this regard. There were no significant differences also between groups in practiced days per week leisure-time PA (walking $p=.069$, moderate PA $p=.095$, vigorous PA $p=.256$ ). The average value of MET-min/week for vigorous PA during leisure time was significantly higher declared $(p=.03)$ by the yuppie/muppie group (628.7 \pm 1415.5 vs. $345.8 \pm 1073.4$ MET-min/ week). Conclusions: Yuppies and muppies cannot be regarded as a role model for Polish society in terms of taking up active leisure-time activities and meeting World Health Organization recommendations. Thus, it seems valuable to carry out further research in order to find role-model groups within the population aged 20-39.
\end{abstract}

Keywords: physical activity, lifestyle, health promotion, patterns of behaviour, young people, IPAQ

\section{Introduction}

An increase in the physical activity (PA) level is a priority goal of public health institutions and governments around the world (The Council of the European Union and the Representatives of the Governments of the Member States, 2011; World Health Organization [WHO], 2018) - especially because of growing concerns against the negative health effects of movement deficiency (Deelen, Ettema, \& Kamphuis, 2018; Grima, Grima, Thalassinos, Seychell, \& Spiteri, 2018). However, still around 60\% of Europeans do not do PA at all or do it too rarely (European Commission, 2014). There are more than half (52\%) of such people in Poland (European Commission, 2014). According to The economic cost of physical inactivity in Europe (International

\footnotetext{
* Address for correspondence: Elżbieta Biernat, Department of Tourism, Collegium of World Economy, SGH Warsaw School of Economics, Al. Niepodległości 162, 02-554 Warsaw, Poland. E-mail: elzbieta.biernat@sgh.waw.pl
}

Sport and Culture Association, 2015), the lack of PA in Polish society results in annual direct healthcare costs of EUR 219 million. Economists' calculations show that these costs can be completely avoided by urging the inactive individuals to make simple changes to their lifestyle, for example, by incorporating exercise into daily or weekly activities (International Sport and Culture Association, 2015).

The process of such a change in behaviour requires continuous analysis of the current state, research on the determinants of participation or lack of PA, and the search for motivating factors. The example of other people - family, friends, various pattern-making groups whose attitude, behaviour and lifestyle can stimulate the actions of others may be important in this respect. One of them are young urban professionals (yuppies), in the 1980s in the USA, they were regarded as an important, political, and cultural force (Carpini \& Sigelman, 1986; Hammond, 1986). Although it seems that discussing this group is nowadays slightly not upto-date (after the financial crisis of 2008, the lifestyle of 
yuppies was not reflected among the young generations in America and 15 countries of the European Union before access of 10 new members in 2004 (Pan, 2017) but in post-transformation countries such as Poland, yuppies' values are current and valid. The yuppie style only reached Poland with its transformation in 1989, making a staggering career in the 1990s and in the first decade of the $21^{\text {st }}$ century. Contemporary Polish yuppies, just like those from the 1980s (Ayto, 2006; Rottenberg, 1980), eagerly set up companies, work in representative offices of Western corporations and state administration (PR News, 2006). They are welleducated, socially aware go-getters. They represent a specific way of life: they participate in culture, eat healthy meals, care about appropriate clothing, choose active forms of spending leisure time in the company of other people (Bernasiewicz, 2013; Giddens, 2013). They care for health, appearance, physical condition and general revitalization (Dekker \& Ester, 1990; Mascarenhas, 2015). As such, they are imitated and identified (Mądrzycki, 1977). We are also talking here about a new generation, in other words, middle-aged urban professionals (muppies), who have a slightly different way of life than yuppies: slow life, organic, eco food, start-up, crowd-funding (Miller, 2015), but the same set of values: the level of ambition, the pursuit of success, status, power and things important for them, for example, they care for their health and physical condition (Bernasiewicz, 2013; Pan, 2017). And like yuppies, they can provide patterns of behaviour and be an attractive determinant of behaviour for many Poles (Bernasiewicz, 2013; Giddens, 2013).

The aim of our work is to analyze PA (efforts taken in leisure time, at work, transportation) of Poles aged 20-39 (762 people). In order to check whether, among young people, the yuppies and muppies (which can be role models of leisure-time behaviour) have a higher leisure-time physical activity than other Poles at this age, 67 representatives of yuppies and muppies and 695 other people at this age were selected from the whole sample. PA of the representatives of these groups was compared and analysed whether it was sufficient to meet pro-health PA dose recommended by the World Health Organization (WHO, 2010).

\section{Methods}

\section{Procedures}

The study was conducted by order of the Polish Ministry of Sport and Tourism on the representative sample of the Poles aged 15+ on two dates (7.-12.10.2016: $N=1053$ and 12.-17.11.2016: $N=1067)$. Surveys were conducted by trained and supervised pollsters from Kantar Public within the Omnibus survey, using Computer-Assisted Personal Interviews. The ethics committee of the Polish Academy of Sciences approved the study (approval nr. KEwN/60/2014) in accordance with the Declaration of Helsinki (2004). All participants provided written informed consent, or legal guardian written informed consent for those under the age of 18 .

\section{Participants}

The sample was random-quote and selected from the sampling frame of the National Official Register of the Territorial Division of the Country (TERYT). The sampling procedure included 3 stages: territorial stratification, drawing addresses, and allocation of demographic characteristics. The stratification considered the size of an inhabited place and territorial arranging within 16 voivodeships. In the selected cities and communes, there was drawn the number of addresses proportional to the number of inhabitants. Addresses were chosen using the systematic sampling method from the TERYT frame (Statistics Poland, 2016a). For the drawn addresses, there were allocated samples considering sex and age cohorts, in accordance with criteria developed by Statistics Poland (Statistics Poland, 2016b).

For the aims of this study (from two bases, i.e., $N=1053$ and $N=1067)$, we selected persons aged 20-39 $(N=762)$. Next, we searched for yuppies and muppies. Belonging to this group was based on the following definition: "is a member of the social category that includes young, well-to-do professionals, living in big cities" (Pacholski \& Słaboń, 2010, p. 228). Acxiom Polska characterises them as those who, in the majority, are in their $30 \mathrm{~s}$, live in big cities, and have a stable financial situation, much better than the average one (PR News, 2006). They prefer more active ways of spending their leisure time: keeping fit (67\%), going to pubs and discos (54\%), and cinema (55\%).

On the basis of the following criteria: (1) higher education, (2) residence in cities of over 100,000 citizens, (3) study skills character of work (managers/ specialists, private entrepreneurs, administration and services workers); there was created a yuppie/muppie group $(n=67)$. The remaining participants $(n=695)$ were called non-yuppies. The characteristics of these groups are presented in Table 1.

\section{Survey design}

The survey contained questions about household (sociodemographic variables and using the Internet) and PA of the respondents. Questions related to PA were based on the Polish Long Form of the International Physical Activity Questionnaire (IPAQ-LF; 
Table 1

Characteristics of the respondents grouped in yuppies/muppies and non-yuppies

\begin{tabular}{|c|c|c|c|c|c|c|}
\hline \multirow[b]{2}{*}{ Variable } & \multicolumn{2}{|c|}{ Yuppies/muppies $(n=67)$} & \multicolumn{2}{|c|}{ Non-yuppies $(n=659)$} & \multicolumn{2}{|c|}{ Total $(N=762)$} \\
\hline & $n$ & $\%$ & $n$ & $\%$ & $n$ & $\%$ \\
\hline \multicolumn{7}{|l|}{ Sex } \\
\hline Male & 29 & 43.3 & 360 & 51.8 & 389 & 51.0 \\
\hline Female & 38 & 56.7 & 335 & 48.2 & 373 & 49.0 \\
\hline \multicolumn{7}{|l|}{ Age } \\
\hline 20-29 years old & 21 & 31.3 & 327 & 47.1 & 348 & 45.7 \\
\hline 30-39 years old & 46 & 68.7 & 368 & 52.9 & 414 & 54.3 \\
\hline \multicolumn{7}{|l|}{ Marital status } \\
\hline Single & 24 & 35.8 & 292 & 42.0 & 316 & 41.5 \\
\hline Married, in relationship & 40 & 59.7 & 382 & 55.0 & 422 & 55.4 \\
\hline Divorced/separated & 1 & 1.5 & 18 & 2.6 & 19 & 2.5 \\
\hline Widowed & 2 & 3.0 & 3 & 0.4 & 5 & 0.7 \\
\hline \multicolumn{7}{|l|}{ Education } \\
\hline Primary & - & - & 48 & 6.9 & 48 & 6.3 \\
\hline Vocational secondary & - & - & 158 & 22.7 & 158 & 20.7 \\
\hline Secondary & - & - & 351 & 50.5 & 351 & 46.1 \\
\hline Higher & 67 & 100.0 & 138 & 19.9 & 205 & 26.9 \\
\hline \multicolumn{7}{|l|}{ Using Internet } \\
\hline Every day or almost every day & 66 & 98.5 & 572 & 82.3 & 638 & 83.7 \\
\hline Several times a week & 1 & 1.5 & 51 & 7.3 & 52 & 6.8 \\
\hline Once a week & - & - & 18 & 2.6 & 18 & 2.4 \\
\hline Several times a month & - & - & 3 & 0.4 & 3 & 0.4 \\
\hline Once a month & - & - & 1 & 0.1 & 1 & 0.1 \\
\hline No access & - & - & 48 & 6.9 & 48 & 6.3 \\
\hline I don't know & - & - & 2 & .3 & 2 & 0.3 \\
\hline \multicolumn{7}{|l|}{ Professional activity } \\
\hline Works professionally & 67 & 100.0 & 500 & 71.9 & 567 & 74.4 \\
\hline Does not work professionally & - & - & 195 & 28.1 & 195 & 25.6 \\
\hline \multicolumn{7}{|l|}{ Occupational status } \\
\hline Manager/specialist & 30 & 44.8 & 54 & 7.8 & 84 & 11.0 \\
\hline Private entrepreneur & 4 & 6.0 & 17 & 2.4 & 21 & 2.8 \\
\hline Administration and service employee & 33 & 49.3 & 181 & 26.0 & 214 & 28.1 \\
\hline Physical worker & - & - & 232 & 33.4 & 232 & 30.4 \\
\hline Farmer & - & - & 16 & 2.3 & 16 & 2.1 \\
\hline Housewife & - & - & 65 & 9.4 & 65 & 8.5 \\
\hline Retiree/pensioner & - & - & 8 & 1.2 & 8 & 1.0 \\
\hline Student & - & - & 63 & 9.1 & 63 & 8.3 \\
\hline Unemployed & - & - & 59 & 8.5 & 59 & 7.7 \\
\hline \multicolumn{7}{|l|}{ Self-assessment of the material situation } \\
\hline Good & 36 & 53.7 & 172 & 24.7 & 208 & 27.3 \\
\hline Average & 28 & 41.8 & 428 & 61.6 & 456 & 59.8 \\
\hline Bad & 3 & 4.5 & 95 & 13.7 & 98 & 12.9 \\
\hline
\end{tabular}

(Table 1 continues) 
Table 1 (continued)

\begin{tabular}{|c|c|c|c|c|c|c|}
\hline \multirow[b]{2}{*}{ Variable } & \multicolumn{2}{|c|}{ Yuppies/muppies $(n=67)$} & \multicolumn{2}{|c|}{ Non-yuppies $(n=659)$} & \multicolumn{2}{|c|}{ Total $(N=762)$} \\
\hline & $n$ & $\%$ & $n$ & $\%$ & $n$ & $\%$ \\
\hline \multicolumn{7}{|c|}{ Average monthly gross income (per capita in household) } \\
\hline$\leq 1,500 \mathrm{PLN}(\leq 350 \mathrm{EUR})$ & - & - & 25 & 3.6 & 25 & 3.3 \\
\hline 1,501-2,500 PLN (350.2-583.3 EUR) & - & - & 61 & 8.8 & 61 & 8.0 \\
\hline$\geq 2,501$ PLN $(\geq 583.5$ EUR $)$ & 36 & 53.7 & 254 & 36.5 & 290 & 38.1 \\
\hline Refusal to answer & 31 & 46.3 & 355 & 51.1 & 386 & 50.7 \\
\hline \multicolumn{7}{|l|}{ Size of the household } \\
\hline $1-2$ persons & 11 & 16.4 & 93 & 13.4 & 104 & 13.6 \\
\hline 3 persons & 21 & 31.3 & 164 & 23.6 & 185 & 24.3 \\
\hline 4 persons & 22 & 32.8 & 218 & 31.4 & 240 & 31.5 \\
\hline 5 persons and more & 13 & 19.4 & 220 & 31.7 & 233 & 30.6 \\
\hline \multicolumn{7}{|l|}{ Place of residence } \\
\hline Village & - & - & 305 & 43.9 & 305 & 40.0 \\
\hline Town to 20,000 inhabitants & - & - & 107 & 15.4 & 107 & 14.0 \\
\hline Town with $20,000-100,000$ inhabitants & - & - & 137 & 19.7 & 137 & 18.0 \\
\hline Town withn $100,000-500,000$ inhabitants & 36 & 53.7 & 87 & 12.5 & 123 & 16.1 \\
\hline Town with over 500,000 inhabitants & 31 & 46.3 & 59 & 8.5 & 90 & 11.8 \\
\hline
\end{tabular}

Biernat, 2013). They asked for each occupational PA (OPA), transport-related PA (TPA), PA in and around the house and leisure-time PA (LTPA).

\section{Data analysis}

In this study, only questions on OPA (vigorous PA [VPA], moderate PA [MPA] and walking), TPA (walking, cycling/roller-skating) and LTPA (VPA, MPA and walking) were analysed. According to the IPAQ methodology (International Physical Activity Questionnaire, 2005), only efforts from the last week, lasting more than $10 \mathrm{~min}$ at one stance, were taken into consideration. On the basis of the duration ( $\mathrm{min} /$ day) and frequency (days/week) of the efforts, OPA, TPA and LTPA indexes (expressed in MET-min/week) of the yuppies/muppies and non-yuppies were calculated. Weekly energy expenditure of the activity was calculated by multiplying a MET number attributed to it (LTPA: vigorous 8 MET, moderate 4 MET, walking 3.3 MET; OPA: vigorous 8 MET, moderate 4 MET, walking 3.3 MET; TPA: cycling/roller-skating 6 MET) by a number of days of practicing it per week and time of duration in min per day (IPAQ, 2005). 1 MET corresponds to the consumption of $\mathrm{O}_{2}$ during resting and equals to $3.5 \mathrm{ml} \mathrm{O}_{2} / \mathrm{kg}$ of body mass per min (Pollock \& Wilmore, 1990).

Considering the fact that sport or physical recreation are, in general, the only occasion for healthenhanced PA(EU Working Group "Sport and Health",
2008; Mynarski et al., 2014) and promotion of models of spending leisure time (Karimian, Hosseini, Shekarchizadeh, \& Nafchi, 2015), LTPA was a subject of detailed evaluation. On the basis of a sum of evaluated indexes of LTPA and TPA, respondents were divided into those meeting and those not meeting the pro-health dose of PA as specified by the World Health Organization (WHO, 2010, 2018). The first group comprised persons having moderate for $\geq 150 \mathrm{~min} /$ week or vigorous PA for $\geq 75 \mathrm{~min} /$ week or walking for $\geq 150 \mathrm{~min} /$ week, or an equivalent of a combination of all activities (LTPA, TPA) exceeding 600 MET-min/week.

\section{Statistical analysis}

Statistical calculations were conducted using IBM SPSS Statistics (Version 22; IBM, Armonk, NY, USA). Descriptive statistics were conducted using the mean, median, standard deviation, or percentage. In order to verify if analysed variables (OPA: VPA, MPA and walking; TPA: walking, cycling/roller-skating; LTPA: VPA, MPA, walking) were characterised by a normal distribution, the Kolmogorov-Smirnov test was used for a single sample. Due to a lack of meeting the above assumption for dependent variables $(p<.05)$, the statistical inference was based on the Mann-Whitney $U$ test. In order to investigate the differences between the types and duration of PA undertaken and the status of yuppies/muppies, the $\chi^{2}$ test was used. The level of significance was set at $\alpha=.05$. 


\section{Results}

In the whole analysed group, the average value of MET-min/week was $2685.6 \pm 4072.2$ for OPA, $896.0 \pm 1099.8$ for TPA, and $869.9 \pm 1604.3$ for LTPA (Table 2). No statistically significant differences were observed between yuppies/muppies and other persons under the study (non-yuppies) in this area, apart from two exceptions. Firstly, the amount of VPA during leisure time was significantly higher $(p=.03)$ among yuppies/muppies $(628.7 \pm 1415.5$ vs. $345.8 \pm 1073.4$ MET-min/week). Secondly, the amount of VPA at work was significantly higher $(p=.038)$ among non-yuppies $(1290.9 \pm 2655.8$ vs. $579.1 \pm 1806.0$ MET-min/week). A similar phenomenon was noted in case of the analysis of the frequency of undertaking PA during a week. The average number days per week of VPA at work was relatively lower $(p=.042)$ among yuppies/muppies $(0.7 \pm 1.7)$ than in case of non-yuppies $(1.2 \pm 2.2)$, while it was opposite in case of the average VPA during leisure $(1.1 \pm 1.9$ vs. $0.7 \pm 1.6$, respectively; $p=.043)$. No statistically significant difference in the average number of days of undertaking particular types of activity per week was found.

There were no significant differences between groups in practiced days per week LTPA, similarly as in case of walking $(p=.069)$, MPA $(p=.095)$, and VPA $(p=0.256)$; see Figure 1. Both among yuppies/ muppies and non-yuppies, walking was most often declared 3 days a week (17.9\% and 9.8\%, respectively). We should note that as much as $41.3 \%$ of yuppies/ muppies and $51.1 \%$ of non-yuppies did not report this type of activity at all. The number of inactive persons in case of MPA was much larger: $77.6 \%$ and $76.5 \%$ (Figure 1). Most often, MPA was declared to happen 2 times a week (7.5\% among yuppies/muppies and 5.8\% for non-yuppies), and VPA 3 times a week (10.4\% and $4.9 \%$, respectively). In the case of VPA, the percentage of inactive ones was $68.7 \%$ and $79.0 \%$, respectively (Figure 1).

The analysis of the duration of LTPA (min/day) revealed significant differences between the groups ( $p=.019$ ) only in the case of MPA (Table 3 ). This type of activity was relatively longer performed by yuppies/muppies (67.2 $\mathrm{min} /$ day) than non-yuppies (47.9 $\mathrm{min} /$ day).

Pro-health recommendations of WHO (considering LTPA) are met by $43.3 \%$ of yuppies/muppies and $33.4 \%$ of non-yuppies. No significant differences between groups in this scope were observed $(p=.103)$.

\section{Discussion}

The main aim of the work was to evaluate whether, in the analysed group of Poles aged 20-39, yuppies/muppies are characterised by higher LTPA in comparison to other people, and, as a result, whether they can be a role model in healthy lifestyle habits. After all, they are regarded as an essential cultural force (Dekker \& Ester, 1990), which can be a motor of fundamental social transformations (Powell, Paluch, \& Blair, 2011) and a subject of identification (Bernasiewicz, 2013; Mądrzycki, 1977; Pan, 2017). The above concerns

Table 2

Physical activity in MET-min/week declared by yuppies/muppies and non-yuppies

\begin{tabular}{lccc}
\hline Physical activity & $\begin{array}{c}\text { Yuppies/muppies } \\
(n=67)\end{array}$ & $\begin{array}{c}\text { Non-yuppies } \\
(n=695)\end{array}$ & $\begin{array}{c}\text { Total } \\
(N=762)\end{array}$ \\
\hline OPA & $1681.4 \pm 3420.6(198.0)$ & $2782.4 \pm 4118.7(598.0)$ & $2685.6 \pm 4072.2(495.0)$ \\
VPA & $579.1 \pm 1806.0(0)$ & $1290.9 \pm 2655.8(0) *$ & $1228.3 \pm 2599.2(0)$ \\
MPA & $557.3 \pm 1159.1(0)$ & $884.5 \pm 1386.2(0)$ & $855.8 \pm 1370.2(0)$ \\
Walking & $545.0 \pm 904.5(0)$ & $607.0 \pm 975.2(0)$ & $601.6 \pm 968.8(0)$ \\
TPA & $809.8 \pm 1004.7(514.8)$ & $904.3 \pm 1108.8(558.0)$ & $896.0 \pm 1099.8(558.0)$ \\
Walking & $629.4 \pm 846.0(396.0)$ & $597.8 \pm 773.1(346.5)$ & $600.6 \pm 779.3(346.5)$ \\
Cycling, roller-skating & $180.5 \pm 418.7(0)$ & $306.5 \pm 745.0(0)$ & $295.4 \pm 722.9(0)$ \\
LTPA & $1112.1 \pm 1562.9(438.0)$ & $846.6 \pm 1783.8(228.0)$ & $869.9 \pm 1604.3(258.0)$ \\
VPA & $628.7 \pm 1415.5(0) *$ & $345.8 \pm 1032.4(0)$ & $370.7 \pm 1073.4(0)$ \\
MPA & $214.3 \pm 657.0(0)$ & $156.5 \pm 465.2(0)$ & $161.6 \pm 484.8(0)$ \\
Walking & $269.1 \pm 314.9(198.0)$ & $344.2 \pm 608.0(0)$ & $337.6 \pm 588.4(0)$ \\
\hline
\end{tabular}

Note. $\mathrm{OPA}=$ occupational physical activity; $\mathrm{VPA}=$ vigorous physical activity; $\mathrm{MPA}=$ moderate physical activity; TPA = transportrelated physical activity; LTPA = leisure-time physical activity. Values are presented as $M \pm S D(M d n)$. *statistically significant difference between yuppies/muppies and non-yuppies. 


\section{Yuppies/muppies}

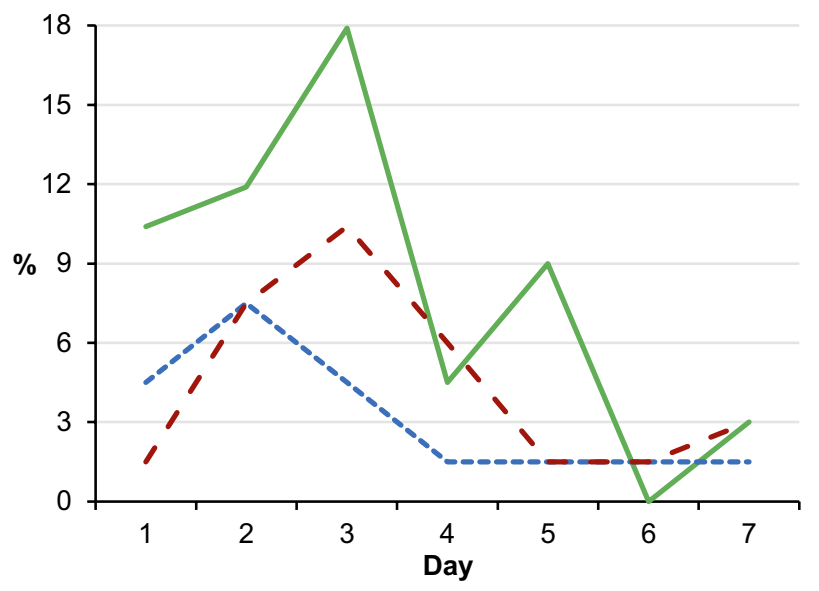

Non-yuppies

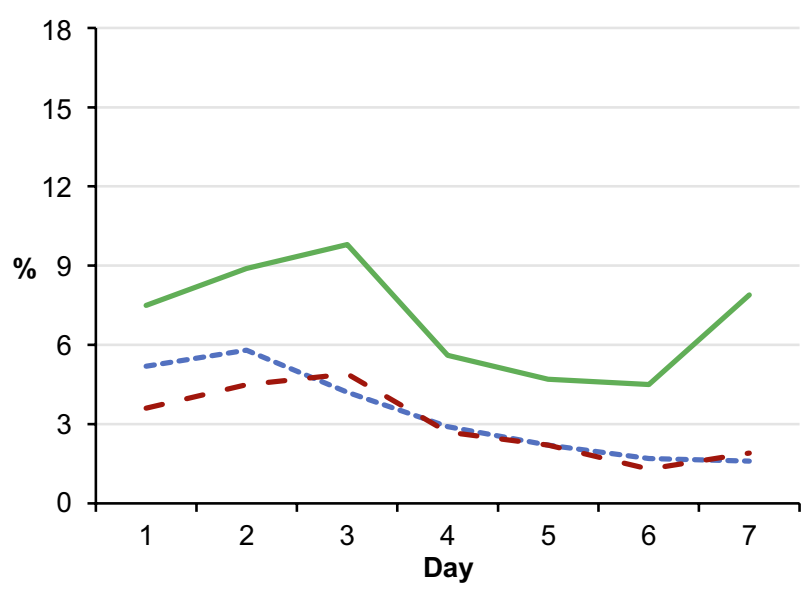

_ - vigorous physical activity _ $\quad---$ moderate physical activity _ walking

Figure 1. Percentage of yuppies/muppies and non-yuppies declaring taking up leisure-time physical activity in days.

Table 3

Leisure-time physical activity in min/day declared by yuppies/muppies and non-yuppies

\begin{tabular}{lccc}
\hline Characteristic & VPA & MPA & Walking \\
\hline Yuppies/muppies $(n=67)$ & & \\
$n$ & 41 & 16 & 23 \\
$M$ & 47.9 & $67.2 *$ & 59.8 \\
$M d n$ & 45.0 & 60.0 & 60.0 \\
$S D$ & 32.7 & 45.3 & 39.4 \\
Non-yuppies $(n=695)$ & & \\
$n$ & 367 & 194 & 178 \\
$M$ & 51.6 & 43.4 & 48.8 \\
$M d n$ & 45.0 & 30.0 & 40.0 \\
$S D$ & 38.1 & 40.3 & 45.0 \\
Total $(N=762)$ & & & \\
$n$ & 408 & 210 & 201 \\
$M$ & 51.2 & 45.2 & 50.0 \\
$M d n$ & 45.0 & 30.0 & 45.0 \\
$S D$ & 37.6 & 41.1 & 44.5 \\
\hline Note. VPA = vigorous & physical activity; & MPA = moderate \\
physical activity. *statistically significant difference between \\
yuppies/muppies and non-yuppies.
\end{tabular}

also pro-health behaviour. In the view of researchers, yuppies/muppies take care of their health, appearance, physical fitness, and general revitalisation (Dekker \& Ester, 1990; Hjorthol \& Bjørnskau, 2016; Karsten, 2016; Mascarenhas, 2015; van der Burgt \& Gustafson, 2013).

Due to the above, LTPA undertaken by representatives of this group was analysed and next compared with the results of other people under the study. It was verified whether the efforts achieve the level recommended by WHO. Results of our research revealed that there are no significant differences in the realisation of pro-health recommendations concerning the physical activity of WHO between yuppies/muppies (43.3\%) and other people aged 20-39 (33.4\%). Thus, we cannot state that the lifestyle of Polish yuppies/muppies can be an indicator of pro-health behaviour for the rest of society. Occupation category/status was directly associated with LTPA, with white-collar/professionals showing the highest LTPA compared to blue-collar workers (Kirk \& Rhodes, 2011). According to Gu et al. (2016), a larger proportion of white-collar compared to blue-collar workers were engaged in "sufficient" (moderate intensity, $\geq 150$ min per week) LTPA (professional/scientific/technical services $62.1 \%$ and life/ physical/social science $66.4 \%$, including those aged 25-34 48.1\%). However, data from Australian studies show that no relationship was observed between the occupational category and engagement in sufficient PA (Duncan, Badland, \& Mummery, 2010). Professionals were more likely to report sufficient levels of PA compared with blue-collar workers (odds ratio 1.19, $95 \%$ confidence interval $[0.78,1.81])$. However, these associations did not achieve statistical significance. A comparison with the results of studies on Polish professional groups shows that the group of yuppies/muppies analysed by us does not outstand. Similar PA level is represented by technical workers employed at public institutions (44.5\%; Biernat, 2015), doctors (48\%; Biernat, Poznańska, \& Gajewski, 2012), and mega-store workers from Warsaw (35.4\%; Biernat \& Tomaszewski, 2012). As it was already mentioned, apart from some 
types of activity, yuppies/muppies do not differ also from other respondents aged 20-39. The differences concern mainly leisure time VPA, in other words, the overall energy expenditure expressed in MET-min/ week and the number of days that were significantly more often noted for the former group.

Undertaking VPA is, of course, a domain of young age and related passion to such type of activity and physical ability to performing it (Pan, 2017). However, this may also indicate a conscious making up for a deficiency of PA. Young people representing a high social and economic class have a problem in finding time for sports activity (Karimian et al., 2015). People starting a family (Leslie et al., 1999), bringing up children (Barnekow-Bergkvist, Hedberg, Janlert, \& Jansson, 1996), starting a new job or working overtime are more vulnerable to a risk of a lack of PA (Dekker \& Ester, 1990). The high socioeconomic status does not completely prevent insufficient activity (Biernat \& Buchholtz, 2016). As a result, being aware of the necessity of realisation of energy expenditure at a certain level (to keep up good health), they undertake vigorous activities, compensating a lack of everyday moderate PA. Studies show that the quality and the characteristics of leisure time and also the nature of its activities depend on the level of people's knowledge, awareness, attitude, and dominant values of different groups of the society (Karimian et al., 2015). We are speaking about a special group: people living in large cities, educated, with a high economic status, being aware of threats brought by civilization (Ayto, 2006). It is a group being aware that PA becomes an important type of individual good, providing capital to an individual (Karimian et al., 2015), including professional efficiency, satisfaction, and health.

\section{Limitations and strengths}

The study has potential limitations. Presented results should be analysed with a certain dose of caution, as, despite the used procedure of studies, (what is described in Methods in detail), the number of people meeting the criteria of yuppies/muppies $(n=67)$ is remarkably lower than of other respondents $(n=695)$. This may limit the possibility of statistical analysis and have a relation with rarely noted statistically significant differences between groups. IPAQ questionnaire was used in the study, which, on the one hand, is a standardised tool developed for population research, on the other hand, due to self-evaluation, it can lead to overestimation or underestimation of PA. It should be also stressed that a modest number of works in the field of this specific group makes references to past results difficult.
Despite the above weaknesses, a strong side of the work is that this is the first study in Poland conducted on a representative sample, analysing PA of yuppies/ muppies in comparison to other persons aged 20-39. In light of our knowledge, as mentioned above, a scarce number of works concern this subject. This indicated the necessity of conducting a further search for a group that could motivate other people to PA. An analysis of the lifestyle of respondents should be essential in future studies. What is more, it must be stressed that the presented study was well designed and extensive, and IPAQ, accurate and reliable, utilised in numerous countries, was used in the evaluation of the level of PA. This gives an opportunity for replication of studies and comparison of results.

\section{Conclusions}

Our study does not acknowledge that yuppies/muppies can be a role model of not only a medium of culture but also to co-create new values in the field of PA by shaping the awareness and habits of active leisure time. The group under the analysis does not differ from other Poles aged 20-39 in the scope of LTPA, as well as realisation of pro-health norms of PA recommended by WHO. More often undertaking of VPA by yuppies/ muppies during leisure time may indicate (although this is just a speculative statement) a will to compensate a lack of time for everyday moderate PA, as well as of their awareness of the necessity of physical activity at a recommended level. According to Bernasiewicz (2013), so far, in Polish society, there are not activated "social forces" (human forces), which can activate the society. Thus, it seems valuable to carry out further research in order to find role-model groups within the population aged 20-39.

\section{Conflict of interest}

There were no conflicts of interest.

\section{References}

Ayto, J. (2006). Movers and shakers: A chronology of words that shaped our age (Rev. ed.). Oxford, United Kingdom: Oxford University Press.

Barnekow-Bergkvist, M., Hedberg, G., Janlert, U., \& Jansson, E. (1996). Physical activity pattern in men and women at the ages of 16 and 34 and development of physical activity from adolescence to adulthood. Scandinavian Journal of Medicine \& Science in Sports, 6, 359-370. 
Bernasiewicz, M. (2013). Yuppie oraz squatter: Globalne style życia $w$ lokalnych środowiskach wychowawczych [Yuppie and squatter: Global lifestyles in local educational environments]. Katowice, Poland: University of Silesia Press.

Biernat, E. (2013). International Physical Activity Questionnaire - Polish long version. Polish Journal of Sports Medicine, 29, 1-15.

Biernat, E. (2015). Factors increasing the risk of inactivity among administrative, technical, and manual workers in Warszawa public institutions. International Journal of Occupational Medicine and Environmental Health, 28, 283-294.

Biernat, E., \& Buchholtz, S. (2016). The regularities in insufficient leisure-time physical activity in Poland. International Journal of Environmental Research and Public Health, 13, 798.

Biernat, E., Poznańska, A., \& Gajewski, A. K. (2012). Is physical activity of medical personnel a role model for their patients. Annals of Agricultural and Environmental Medicine, 19, 707-710.

Biernat, E., \& Tomaszewski, W. (2012). Insufficient level of physical activity among hypermarkets employees. Polish Journal of Sports Medicine, 28, 107-117.

Carpini, M. D., \& Sigelman, L. (1986). Do Yuppies matter? Competing explanations of their political distinctiveness. Public Opinion Quarterly, 50, 502-518.

Deelen, I., Ettema, D., \& Kamphuis, C. B. M. (2018). Sports participation in sport clubs, gyms or public spaces: How users of different sports settings differ in their motivations, goals, and sports frequency. PLOS One, 13, e0205198.

Dekker, P., \& Ester, P. (1990). The political distinctiveness of young professionals: "Yuppies" or "New Class"? Political Psychology, 11, 309-330.

Duncan, M. J., Badland, H. M., \& Mummery, W. K. (2010). Physical activity levels by occupational category in nonmetropolitan Australian adults. Journal of Physical Activity \& Health, 7, 718-723.

EU Working Group "Sport and Health". (2008). EU Physical Activity Guidelines: Recommended policy actions in support of health-enhancing physical activity. Retrieved from https:// ec.europa.eu/assets/eac/sport/library/policy_documents/ eu-physical-activity-guidelines-2008_en.pdf

European Commission. (2014). Special Eurobarometer 412. Sport and physical activity. Retrieved from https://ec.europa. eu/health//sites/health/files/nutrition_physical_activity/ docs/ebs_412_en.pdf

Giddens, A. (2013). Europe in the global age. Hoboken, NJ: John Wiley \& Sons.

Grima, S., Grima, A., Thalassinos, E., Seychell, S., \& Spiteri, J. V. (2018). A study of the determinants of sports participation by Maltese nationals. European Research Studies Journal, 21, 110-133.

Gu, J. K., Charles, L. E., Ma, C. C., Andrew, M. E., Fekedulegn, D., Hartley, T. A., ... Burchfiel, C. M. (2016). Prevalence and trends of leisure-time physical activity by occupation and industry in U.S. workers: The National Health Interview Survey 2004-2014. Annals of Epidemiology, 26, 685-692.

Hammond, J. L. (1986). Yuppies. Public Opinion Quarterly, 50, 487-501.
Hjorthol, R. J., \& Bjørnskau, T. (2016). Gentrification in Norway. European Urban and Regional Studies, 12, 353-371.

International Physical Activity Questionnaire. (2005). Guidelines for the data processing and analysis of the "International Physical Activity Questionnaire - Short and Long Forms". Retrieved from https://sites.google.com/site/ theipaq/scoring-protocol

International Sport and Culture Association. (2015). The economic cost of physical inactivity in Europe. An ISCA / Cebr report. Retrieved from https://inactivity-time-bomb. nowwemove.com/download-report/The $\% 20$ Economic $\% 20$ Costs $\% 20$ of $\% 20$ Physical $\% 20$ Inactivity $\% 20$ in $\% 20$ Europe\%20(June\%202015).pdf

Karimian, J., Hosseini, T. A., Shekarchizadeh, P., \& Nafchi, S. M. M. (2015). The relationship between social capital and the way of spending leisure time, based on physical activities. Journal of Education and Health Promotion, 4, 79.

Karsten, L. (2016). Family gentrifiers: Challenging the city as a place simultaneously to build a career and to raise children. Urban Studies, 40, 2573-2584.

Kirk, M. A., \& Rhodes, R. E. (2011). Occupation correlates of adults' participation in leisure-time physical activity: A systematic review. American Journal of Preventive Medicine, 40, 476-485.

Leslie, E., Owen, N., Salmon, J., Bauman, A., Sallis, J. F., \& Lo, S. K. (1999). Insufficiently active Australian college students: Perceived personal, social, and environmental influences. Preventive Medicine, 28, 20-27.

Mądrzycki, T. (1977). Psychologiczne prawidtowości ksztattowania sie postaw [Psychological regularities of attitude formation]. Warsaw, Poland: Wydawnictwa Szkolne i Pedagogiczne.

Mascarenhas, O. A. J. (2015). Identifying and profiling the yuppie baby boomer segment. In K. D. Bahn (Ed.), Proceedings of the 1988 Academy of Marketing Science (AMS) Annual Conference (pp. 13-17). Cham, Switzerland: Springer.

Miller, M. (2015). Meet the muppies: A beginner's guide to 'millenium yuppies'. Irish Times Culture. Retrieved from https://www.irishtimes.com/culture/books/meet-the-muppies-a-beginner-s-guide-to-millenium-yuppies-1.2308583

Mynarski, W., Grabara, M., Nawrocka, A., Niestrój-Jaworska, M., Wołkowycka, B., \& Cholewa, J. (2014). Rekreacyjna aktywność fizyczna i dolegliwości mieśniowo-szkieletowe pielegniarek [Physical recreational activity and musculoskeletal disorders in nurses]. Medycyna pracy, 65, 181-188.

Pacholski, M., \& Słaboń, A. (2010). Stownik pojęć socjologicznych [Dictionary of sociological terms]. Krakow, Poland: Wydawnictwo Uniwersytetu Ekonomicznego.

Pan, J. C. (2017). The New Yuppies. New Republic, 248(8/9), 69-71.

Pollock, M. L., \& Wilmore, J. H. (1990). Exercise in health and disease: Evaluation and prescription for prevention and rehabilitation (2nd ed.). Philadelphia, PA: W. B. Saunders.

Powell, K. E., Paluch, A. E., \& Blair, S. N. (2011). Physical activity for health: What kind? How much? How intense? On top of what? Annual Review of Public Health, 32, 349-365.

PR News. (2006). Mtodzi, wyksztatceni i dobrze zarabiajacy - czyli Yuppies z bazy Acxiom [Young, educated 
and well-earned - the Yuppies from the Acxiom base]. Retrieved from https://prnews.pl/mlodzi-wyksztalceni-idobrze-zarabiajacy-czyli-yuppies-z-bazy-acxiom-76190

Rottenberg, D. (1980). About that urban renaissance... ... there'll be a slight delay. Chicago Magazine. Retrieved from https://www.chicagomag.com/Chicago-Magazine/May-1980/ Yuppie/

Statistics Poland. (2016a). TERYT Register. Voivodships, powiats, gminas, streets. Retrieved from http://eteryt.stat.gov.pl/ eTeryt/english.aspx

Statistics Poland. (2016b). Ludność. Stan i struktura ludności oraz ruch naturalny $w$ przekroju terytorialnym. Stan $w$ dniu 31 grudnia 2015 roku [Population. The state and structure of the population and natural movement in the territorial section. Status on 31 December 2015]. Retrieved from https:// stat.gov.pl/obszary-tematyczne/ludnosc/ludnosc/ludnoscstan-i-struktura-ludnosci-oraz-ruch-naturalny-w-przekrojuterytorialnym-stan-w-dniu-31-grudnia-2015-roku,6,19.html
The Council of the European Union and the Representatives of the Governments of the Member States. (2011). Resolution of the Council and of the Representatives of the Governments of the Member States, meeting within the Council, on a European Union Work Plan for Sport for 2011-2014: 2011/C 162/01. Retrieved from https://eur-lex.europa.eu/ legal-content/EN/TXT/HTML/?uri=CELEX:42011Y060 $1(01) \&$ from $=\mathrm{EN}$

Van der Burgt, D., \& Gustafson, K. (2013). "Doing Time" and "Creating Space": A case study of outdoor play and institutionalized leisure in an urban family. Children, Youth and Environments, 23, 24.

World Health Organization. (2010). Global recommendations on physical activity for health. Geneva, Switzerland: Author. World Health Organization. (2018). More active people for a healthier world: Global action plan on physical activity 2018-2030. Geneva, Switzerland: Author. 